Australian wool'. Sir Joseph Banks, then president of the Royal Society, was also interested in the introduction of breeds of sheep into Australia, and received fleeces from Macarthur which were reported upon by H. Laycock. Banks, in fact, had many dealings with Capt. Macarthur concerning sheep and wool and also grants of land, some leading to acrimonious letters and mutual distrust. These may well be viewed by posterity with lenient tolerance, as being perhaps inevitable on both sides with the masterful types of men who were then involved in discussions affecting methods of colonisation. Macarthur died in 1834 .

\section{Photochemical Reactions}

As admirable account of the history and present position of photochemistry was given by Prof. A. J. Allmand, of King's College, London, in delivering the twenty-seventh. Bedson Lecture at Armstrong College, Newcastle-upon-Tyne, on October 27. Tracing it from the work of Cruikshank and Scheele to that of Planck, Einstein and Warburg, he gave a concise account of the interpretation of absorption spectra, and the conception of activation, along with the application of kinetics to photochemical reactions, with consideration also of sensitised reactions. $\mathrm{He}$ related that the German chemical warfare records mentioned the difficulty experienced in the complete chlorination of methyl formate, in which the yield obtained varies apparently capriciously from eighty to about two per cent. This was actually due, as Luther had shown for the homologues of benzene, to the absence or presence of air, oxygen being a powerful inhibitor. Further, it has been shown that under various conditions reaction tends to vary as the square root of light intensity, instead of being directly proportional to it, and in the case of the decomposition of hydrogen peroxide a maximum is reached in the plot of concentration against rate. In the combination of hydrogen with chlorine, intensive drying does not in fact inhibit the reaction. In the sensitisation of the decomposition of ozone by chlorine, there is formation of the oxide $\mathrm{Cl}_{2} \mathrm{O}_{6}$. In the bromination of benzene in the light, the red or brown liquid residues were found to contain $\mathrm{C}_{6} \mathrm{H}_{6} \mathrm{Br}_{2}$, and possibly $\mathrm{C}_{6} \mathrm{H}_{6} \mathrm{Br}_{4}$. Summarising, Prof. Allmand said that photochemical reactions tend to be complex, consisting of consecutive interactions of the free groups or atoms which are the primary products.

\section{A Fast American Stream-line Train}

IN France, the United States, Germany, Italy and Great Britain, experiments are being made with train units driven at high speed by internal combustion engines. The carriages are constructed of either stainless steel or aluminium, all weights are reduced to a minimum and the trains are stream-lined to lessen so far as possible the resistance due to the air. Oil or petrol engines are used, generally with electric transmission. Several of these train units have been described in our contemporaries, the Engineer and Engineering, and the Times of October 26 recorded a very fast passage made across the United States by a stream-line train belonging to the Union
Pacific Railroad. This train, named $M$ 10001, which it is stated is driven by a 900 h.p. Diesel engine, arrived at the Grand Central Terminal, New York, at 9.55 o'clock on October 25, after crossing from Los Angeles in 56 hours 55 minutes, beating every existing record in America. During the passage of the 508 miles between Cheyenne and Omaha, the train had an average speed of 84 miles an hour, while over short distances it ran at 120 miles an hour. The train with two. others, larger and more powerful, which are being built, will be put in regular service between Chicago and California.

\section{Centenary of Lloyd's Register}

THE world-famous society, Lloyd's Register of Shipping, celebrated on October 25 the centenary of its reconstitution by a dinner at the Savoy Hotel, which was attended by about four hundred distinguished guests, members of the staff and representatives of various shipping and commercial interests. The society has been described as a voluntary association of underwriters, shipowners, shipbuilders and others existing for the purpose of surveying and classifying the shipping of the world. It provides a means of self-government for shipping, and is neither State-aided nor a profit-making concern. Of British shipping, more than three quarters is at present classed with Lloyd's Register, and of the ships being built throughout the world, 74 per cent are being constructed under the society's supervision. Its surveyors are found in every important seaport in the world, and in paying a tribute to its work, Mr. Runciman, the president of the Board of Trade, said that for many years Lloyd's Register has classified more ships than all the other classification societies in the world, and it has done so on an international basis which has given uniformity to the trade it has served so well. It has standardised the basis of material and design, and has made a contribution to the safety of travel which could not have been made by any other means. The society is shortly publishing a centenary edition of the "Annals of Lloyd's Register", which will contain a wealth of information anent the development of merchant shipbuilding from the days of the wooden ship to the launch of the Queen Mary.

\section{Texture and Chemical Resistance of Materials}

Dr. C. H. Desch delivered a public lecture on October 26 before the Institution of Chemical Engineers on "Texture and Chemical Resistance". Dr. Desch pointed out that the resistance of materials of construction to attack by chemical agents depends not only on their composition, both ultimate and proximate, but also on their texture. This is illustrated by the differences between the behaviour of wrought iron and mild steel, the attack of sulphates on limestone, and the action of hard and soft waters on concrete dams. On a finer scale, the resistance of metals and alloys to chemical attack is affected by the grain size, the presence of cold-worked regions, the smoothness of the surface, and the directional effects of rolling and drawing. In steels, the distribu- 